\title{
STUDY OF THE ASSOCIATION OF SERUM 25-HYDROXYVITAMIN D LEVELS WITH THE GLYCAEMIC CONTROL IN TYPE 2 DIABETES MELLITUS AT A TERTIARY CARE HOSPITAL IN GOA
}

\author{
Chitralekha Anilkumar Nayak1, Anar Viraj Khandeparkar ${ }^{2}$
}

${ }^{1}$ Senior Resident, Department of Medicine, Goa Medical College.

${ }^{2}$ Associate Professor, Department of Medicine, Goa Medical College.

\begin{abstract}
\section{BACKGROUND}

Vitamin D deficiency is widely prevalent across all ages, races, geographical regions and socioeconomic strata. There is ample evidence indicating role of vitamin D in insulin secretion and insulin resistance in patients with type 2 diabetes mellitus. Evidence shows that Vitamin D deficiency can affect the glycaemic control in type 2 diabetes mellitus.

Objective- To study the association between serum 25-hydroxyvitamin D levels with glycaemic control in patients of type 2 diabetes mellitus.
\end{abstract}

\section{MATERIALS AND METHODS}

This case series study was performed on 50 consecutive patients of type 2 diabetes mellitus of 30 to 60 years admitted in General Medicine Ward at Goa Medical College. Serum 25-hydroxyvitamin D levels were assessed using Fully Automated Chemiluminescent Immunoassay (CLIA). Patients with renal failure, type 1 diabetes, chronic illness, pregnancy, thyroid disorders and previous intake of calcium and vitamin D were excluded from the study. The relationship between serum 25-hydroxyvitamin D levels and HbA1c, fasting blood glucose and postprandial blood glucose levels was assessed.

\section{RESULTS}

$72 \%$ of the study population had vitamin D deficiency and $26 \%$ of the study group had insufficiency of the vitamin and the remaining $2 \%$ had normal 25-hydroxyvitamin D levels. The type 2 diabetic individuals with vitamin D deficiency showed a poor glycaemic control as evidenced by inverse relationship of serum vitamin D levels with FBSL and PPBSL values. There was inverse association between the low serum 25-hydroxyvitamin D levels and elevated HbA1c in the study population.

\section{CONCLUSION}

Vitamin D deficiency may be associated with impairment of glycaemic control in type 2 diabetes mellitus.

\section{KEYWORDS}

Vitamin D, 25-Hydroxyvitamin D, 25-(OH) D, Diabetes Mellitus, Glycaemic Control.

HOW TO CITE THIS ARTICLE: Nayak CA, Khandeparkar AV. Study of the association of serum 25-hydroxyvitamin D levels with the glycaemic control in type 2 diabetes mellitus at a tertiary care hospital in Goa. J. Evolution Med. Dent. Sci. 2017;6(38):3087-3090, DOI: $10.14260 /$ Jemds/2017/666

\section{BACKGROUND}

As per WHO estimates, prevalence of diabetes may reach 299 million by year 2025 and it is projected to be the leading cause of death by $2030 .{ }^{1}$ Vitamin D deficiency is widely prevalent and it is known to contribute to many conditions like osteomalacia, osteoporosis, falls and fractures. Epidemiological studies have associated low vitamin D status with an increased risk of non-musculoskeletal conditions such as cancer, multiple sclerosis, diabetes mellitus and cardiovascular diseases. Evidence from studies suggests that vitamin D supplementation may help prevent type 2 diabetes mellitus in population at risk of diabetes and also to reduce incidence of complications in known diabetes individuals. The present study was undertaken as limited numbers of studies have attempted to determine the association of serum

Financial or Other, Competing Interest: None.

Submission 17-03-2017, Peer Review 30-04-2017,

Acceptance 06-05-2017, Published 11-05-2017.

Corresponding Author:

Dr. Chitralekha Anilkumar Nayak,

Rukmini, La Marcela Colony,

Marcela-403107, Goa.

E-mail: nayakchitralekha@gmail.com

DOI: $10.14260 /$ jemds $/ 2017 / 666$ 25-hydroxyvitamin D levels with glycaemic control in type 2 diabetes mellitus.

\section{Objectives}

To study the association between serum 25-hydroxyvitamin D levels and impairment of glycaemic control in patients of type 2 diabetes mellitus.

\section{MATERIALS AND METHODS}

The present case series study was performed on 50 consecutive patients of type 2 diabetes mellitus of 30 to 60 years admitted in the Department of Medicine at Goa Medical College from March 2013 to July 2014 upon approval by the Institutional Ethics Committee of the Goa Medical College and Hospital. Informed consent was obtained from all study participants. Serum 25-hydroxyvitamin D levels were measured and its relationship with glycaemic control was assessed among all the study participants.

\section{Inclusion Criteria}

- Age between 30 to 60 years.

- $\quad$ Type 2 diabetes mellitus.

- Indian national. 


\section{Exclusion Criteria}

- Serum creatinine $>1 \mathrm{mg} / \mathrm{dL}$.

- Preexisting chronic cardiac, hepatic, renal and oncologic disease.

- $\quad$ Subjects with type 1 diabetes mellitus.

- Pregnancy and lactation.

- Preexisting thyroid and parathyroid disorders.

- Use of drugs affecting the lipid profile or calcium and bone metabolism.

- History of intake of vitamin D as dietary supplements.

- Preexisting rickets, osteomalacia.

- Patients having disorders that change the metabolism of vitamin D.

- Patients who have been on anticonvulsants, hormone replacement therapy and steroids.

After overnight fasting, $10 \mathrm{~mL}$ of peripheral blood was withdrawn. The following biochemical investigations were performed: fasting blood glucose, 2-hour postprandial blood sugar, HbA1c, serum 25-hydroxyvitamin D, calcium, phosphorus, blood urea, serum creatinine, liver function test and lipid profile.

Total 25-hydroxyvitamin D levels were measured in Thyrocare Laboratory, Panaji and analysed on Siemens ADVIA Centaur, standardised against ID-LC/MS/MS, as per Vitamin D Standardisation Program (VDSP). The technology used was Fully Automated Chemiluminescent Immunoassay (CLIA).

\section{follows- \\ 1. Less than $20 \mathrm{ng} / \mathrm{mL}$ - vitamin D deficiency. \\ 2. 20 to $30 \mathrm{ng} / \mathrm{mL}$ - vitamin D insufficiency. \\ 3. $30-100 \mathrm{ng} / \mathrm{mL}$ - normal levels. \\ 4. $>100 \mathrm{ng} / \mathrm{mL}$ - vitamin D toxicity.}

Serum 25-Hydroxyvitamin D Levels were interpreted as

All other biochemical investigations were performed in biochemistry laboratory of Goa Medical College using Automated Analyser. Detailed history of the patients was taken regarding occupation, sunlight exposure and intake of foods rich in vitamin $\mathrm{D}$, duration of diabetes, treatment and family history of diabetes. Patients were also evaluated for neuropathy and retinopathy. The data was analysed on SPSS software and correlation coefficients were calculated.

The Study Group was categorised into Groups Based on Duration of Diabetes-

1. Less than 1 year, which also included newly detected subjects.

2. 1 to 5 years.

3. 5 to 10 years.

4. $\geq 0$ years.

\section{RESULTS}

A total of 50 patients were included in this study, 32 being males and 18 females. Mean age was $51.5 \pm 7.18$ years. Mean age was $52.7 \pm 7.08$ years in males and $49.2 \pm 6.94$ years in females; $72 \%$ of these diabetic patients were working indoors and $28 \%$ were working outdoors. Most of the people who were working indoors were either involved in clerical jobs or were housewives; $60 \%$ of the study population had diabetes of duration 1 - 5 years, while $14 \%$ were diabetic since 5 - 10 years. In this study, $72 \%$ of the subjects were severely deficient in vitamin D and $26 \%$ of the subjects were insufficient in vitamin D. The remaining $2 \%$ had normal vitamin D levels. This study also showed that $75 \%$ of male study groups were vitamin D deficient, while $21.8 \%$ had vitamin D insufficiency; $3 \%$ of males had normal vitamin D levels; $66 \%$ of female subjects were vitamin D deficient and $33.33 \%$ were insufficient in vitamin D; $66.66 \%$ of severely vitamin D deficient patients were working indoors and $33.34 \%$ were working outdoors; $76.92 \%$ of vitamin D insufficient were working indoors and $23.08 \%$ were working outdoors; $94.44 \%$ of the patients with $25-\mathrm{OH}-\mathrm{D}$ deficiency and $100 \%$ of the patients with insufficiency spent less than 6 hours under sunlight outdoors per day.

\begin{tabular}{|c|c|c|c|}
\hline $\begin{array}{c}\text { Serum Vitamin D } \\
\text { Levels (ng/mL) }\end{array}$ & Males & Females & Total \\
\hline$<20$ & 24 & 12 & 36 \\
\hline $20-30$ & 7 & 6 & 13 \\
\hline $30-100$ & 1 & 0 & 1 \\
\hline$>100$ & 0 & 0 & 0 \\
\hline Figure 1. 25-Hydroxyvitamin D Level Distribution \\
among Study Group \\
\hline
\end{tabular}

\begin{tabular}{|c|c|c|c|}
\hline \multirow[b]{2}{*}{ Mean Variable } & \multicolumn{3}{|c|}{ Serum Vitamin D Levels (ng/mL) } \\
\hline & $\begin{array}{l}<20 \mathrm{ng} / \mathrm{mL} \\
\text { (Deficiency) }\end{array}$ & $\begin{array}{l}20-30 \mathrm{ng} / \mathrm{mL} \\
\text { (Insufficiency) }\end{array}$ & $\begin{array}{c}\text { Total } \\
\text { (49 Patients) }\end{array}$ \\
\hline Age (years) & $49.4 \pm 4.24$ & $50.24 \pm 3.15$ & $51.5 \pm 7.18$ \\
\hline \begin{tabular}{|c|} 
Duration of \\
Diabetes (yrs.)
\end{tabular} & $4.36 \pm 1.28$ & $3.8 \pm 1.43$ & $3.88 \pm 1.75$ \\
\hline FBSL $(\mathrm{mg} / \mathrm{dL})^{*}$ & $213.86 \pm 85.6$ & 200.69 & $208.48 \pm 84.6$ \\
\hline $\begin{array}{c}\text { PPBSL } \\
(\mathrm{mg} / \mathrm{dL}) \dagger\end{array}$ & $321.17 \pm 105.1$ & $289.15 \pm 100.23$ & $308 \pm 112.56$ \\
\hline HbA1C (\%) s & $10.30 \pm 2.01$ & $9.3 \pm 1.95$ & $9.824 \pm 2.36$ \\
\hline $\begin{array}{l}\text { Serum Calcium } \\
(\mathrm{mg} / \mathrm{dL})\end{array}$ & $8.625 \pm 1.33$ & $8.669 \pm 1.78$ & 1.86 \\
\hline \multicolumn{4}{|c|}{$\begin{array}{c}\text { Figure 2. Characteristics of Participants } \\
\text { by Vitamin D Status }\end{array}$} \\
\hline
\end{tabular}

*Fasting plasma glucose levels $\uparrow 2$ hours post prandial plasma glucose levels ş glycosylated haemoglobin.

The study showed a negative correlation of serum vitamin D levels with FBSL values and glycosylated haemoglobin, but was statistically insignificant. It also showed inverse significant association between vitamin D and post prandial blood glucose levels.

\begin{tabular}{|c|c|c|}
\hline \multirow[b]{2}{*}{ Variable } & \multicolumn{2}{|c|}{ Statistical Values } \\
\hline & $\begin{array}{c}\text { Correlation } \\
\text { Coefficient }\end{array}$ & $P$ value \\
\hline FBSL $(\mathrm{mg} / \mathrm{dL})^{*}$ & -0.188 & 0.1905 \\
\hline PPBSL(mg/dL)† & -0.3968 & 0.00433 \\
\hline HbA1C (\%) s & -0.1299 & 0.435 \\
\hline Serum Calcium (mg/dL) & 0.094 & 0.258 \\
\hline \multicolumn{3}{|c|}{$\begin{array}{c}\text { Figure 3. Correlation Coefficients of Variables with } 25 \\
\text { Hydroxyvitamin D Levels }\end{array}$} \\
\hline
\end{tabular}

*Fasting plasma glucose levels $\uparrow 2$ hours post prandial plasma glucose levels ş glycosylated haemoglobin. 


\section{DISCUSSION}

The present study indicated that $72 \%$ of the study population was severely deficient in vitamin D i.e. $25-(\mathrm{OH})$ D levels $<20$ $\mathrm{ng} / \mathrm{mL}$, while $26 \%$ of the study group was insufficient in vitamin D i.e. $25-(\mathrm{OH})$ D levels $20-30 \mathrm{ng} / \mathrm{mL}$ and the remaining $2 \%$ had normal $(25-\mathrm{OH}) \mathrm{D}$ levels. None were found to be in toxic range group, i.e. $25-(\mathrm{OH})$ D levels $>100 \mathrm{ng} / \mathrm{mL}$. Correlating with the result of the present study was the study by Lalitha A et $\mathrm{al}^{2}$ in Vishakhapatnam who observed 38\% of subjects being severely deficient (< $10 \mathrm{ng} / \mathrm{mL}), 42 \%$ moderately deficient and $20 \%$ being insufficient in the vitamin implying that $80 \%$ of the study population was deficient. In contrast to this, severe vitamin D deficiency group comprised of $58.34 \%$ and insufficiency of $41.66 \%$ in a study done by Saedisomeolia et $\mathrm{al}^{3}$ in Iran. Results of another study by Dalgard et $\mathrm{al}^{4}$ on 158 type 2 diabetic patients indicate that more than $50 \%$ of the study group was vitamin D deficient, which is actually lower than present study results.

Thus, it is observed that the incidence of vitamin D deficiency is at least $10 \%$ higher in the present study and the study by Lalitha $\mathrm{A}$ et $\mathrm{al}^{2}$ which can be explained by skin colour, lifestyle factors and ethnic differences. An interesting fact was observed that $27 \%$ of the vitamin D deficient patients had levels below $10 \mathrm{ng} / \mathrm{mL}$ correlating with the previous study by Doddamani et $\mathrm{al}^{5}$ where $20 \%$ of the patients had such levels.

Data depicted that mean age of vitamin D deficiency patients was $49.4 \pm 4.24$ years and that of insufficiency being $50.24 \pm 3.15$ years. Study by Saedisomeolia et $\mathrm{al}^{3}$ also found similar mean age in deficient patients i.e. $47.66 \pm 12.38$ years and $47.63 \pm 11.8$ years in insufficient subjects. $P$ value in both studies was statistically insignificant (present study: 0.1073, Saedisomeolia et al 0.74), thereby ignoring age as a factor for vitamin D deficiency. In our study, age had an inverse relationship with serum vitamin D levels but was statistically insignificant probably due to small sample size.

The data showed that $75 \%$ of male study group were vitamin D deficient, while $21.8 \%$ had vitamin D insufficiency; $3 \%$ of males had normal vitamin D levels; $66 \%$ of female subjects were vitamin D deficient and $33.33 \%$ were insufficient in vitamin $\mathrm{D}$. The difference in number of vitamin D deficient patients between two genders (66\% males, $33 \%$ females) can be attributed to unequal size of sample population. This finding is in contrast with the results of Saedisomeolia et al study, ${ }^{3}$ where $42.9 \%$ males and 57\% females were deficient in vitamin. Of patients with vitamin D insufficiency $53.8 \%$ were males and $46.15 \%$ were females similar to Saedisomeolia et al $^{3}$ where $62.2 \%$ were males and $37.8 \%$ were females. This can be attributed to the equal sample size for both genders in their study. The statistically reverse results in our study may be due to unequal sample population, the type of clothing, hours of sunlight exposure.

25 -hydroxyvitamin D levels were suboptimal in diabetic patients pursuing indoor occupation. Data explains $66.66 \%$ of severely deficient patients were working indoors and $33.34 \%$ were working outdoors; $76.92 \%$ of vitamin D insufficient group was working indoors and $23.08 \%$ was working outdoors. Similar study in diabetic population is lacking in literature for comparison, but a study by Sari et al ${ }^{6}$ in general population depicted $72 \%$ of vitamin D deficient patients working indoors and $27 \%$ working outdoors, results being consistent with the present study.

Another factor which may influence Vitamin D levels is duration of type 2 diabetes mellitus. In this study, mean duration of type 2 diabetes in patients with vitamin D deficiency $(<20 \mathrm{ng} / \mathrm{L}$ ) was 4.36 years and 3.8 years in those with insufficient vitamin levels respectively. Contrary to this, a study by Christel Joergensen et $\mathrm{al}^{7}$ showed mean diabetes duration of 11 years in vitamin deficient subjects and 6 years in patients with insufficient vitamin D levels of $>20 \mathrm{ng} / \mathrm{mL}$. Another study by Ahmadieh et $\mathrm{al}^{8}$ showed no difference in mean diabetes duration between the two vitamin $\mathrm{D}$ groups (Mean duration of diabetes- 8 years). The present study observed a trend of inverse association between vitamin $\mathrm{D}$ levels and duration of diabetes, but it was not statistically significant ( $p$ value: 0.26 ). This study had small sample size and excluded nephropathy patients, while in other studies large population was recruited and subjects with nephropathy were also included.

Considering the glycaemic control of diabetes mellitus, the current study showed an inverse but insignificant relationship of serum vitamin D levels and FBSL values $(r=-0.188, p=$ $0.1905)$. This was consistent with the results of study done by Balasubramanian et $\mathrm{al}^{9}{ }^{9}$ which also showed negative correlation of serum vitamin D levels with fasting blood sugar values and did not show statistical significance $(r=-0.093, p=$ 0.534). This may be attributed to smaller sample size in our study. Studies by Saedisomeolia et $\mathrm{al}^{3}$ and Doddamani GB et $\mathrm{al}^{5}$ showed that mean levels of FBSL were significantly higher in diabetic patients with vitamin D deficiency than those with insufficiency. (Mean FBSL $145 \pm 75.66$ in deficiency and $129 \pm$ 53.38 insufficiency). The present study revealed similar results. The mean FBSL in deficiency group and insufficiency was 213.86 and $200.69 \mathrm{mg} / \mathrm{dL}$ respectively. Contrary to the above, Orwol et al $1994^{10}$ proved no correlation of vitamin D with fasting glucose levels. Many studies conducted on normal glucose tolerant subjects, e.g. studies by Scragg et al 2004,11 Chonchol and Scragg et al 2007,12 Lu et al 2009,13 Need et al 2005,14 Gamnage Yaered et al 2009, Ford et al $2005^{15}$ also found an inverse relationship of serum vitamin concentration with fasting glucose levels.

The results of the present study revealed a trend towards an inverse vitamin $\mathrm{D}$ and post prandial blood glucose levels association, which was statistically significant ( $r=-0.3968, p=$ 0.00433). Similar results were obtained by Balasubramanian et al, ${ }^{9}$ but a statistically insignificant $\mathrm{p}$ value was obtained $(\mathrm{r}=$ -0.095, $\mathrm{p}=0.511$ ). A study by Chiu et al $2004^{16}$ also showed negative correlation $25(\mathrm{OH})$ D levels with PPBSL values. On the contrary, Baynes et al 199717 study did not show any association between the two variables.

The low serum vitamin D levels were negatively correlated with glycosylated haemoglobin value, which was not statistically significant probably due to smaller study group. Studies by Balasubramanian et al $(\mathrm{r}=-0.173, \mathrm{p}=$ $0.229)^{9}$ and Dalgard et $\mathrm{al}^{4}$ found similar inverse association between the two variables. Contrary to this, Saedisomeolia et $\mathrm{al}^{6}$ study and Christel Joergensen et $\mathrm{al}^{6}$ study did not show any association between HbA1c and vitamin D levels. In our study, mean $\mathrm{HbA1c}$ values were higher in vitamin $\mathrm{D}$ deficient 
individuals (mean: 10.30\%) compared to patients with vitamin insufficiency (mean: 9.3\%). Consistent with these results were those of studies by Hypponen and Power et al, ${ }^{18}$ Doddamani et $\mathrm{al}^{5}$ Saedisomeolia et $\mathrm{al}^{3}$ and Christel Joergensen et al. 6

\begin{tabular}{|c|c|c|c|c|}
\hline \multirow{2}{*}{$\begin{array}{c}\text { 25- } \\
\text { Hydroxyvitamin } \\
\text { D Levels (ng/L) }\end{array}$} & \multicolumn{4}{|c|}{ HbA1c (Glycosylated Haemoglobin) } \\
\cline { 2 - 5 } & $<\mathbf{6 \%}$ & $\mathbf{6 - 8 \%}$ & $\mathbf{8} \mathbf{8 \%}$ & Total \\
\hline$<20$ & 0 & 12 & 24 & 36 \\
\hline $20-30$ & 0 & 5 & 8 & 13 \\
\hline $30-100$ & 0 & 0 & 1 & 1 \\
\hline$>100$ & 0 & 0 & 0 & 0 \\
\hline
\end{tabular}

\section{CONCLUSION}

$72 \%$ of the study population had vitamin D deficiency and $26 \%$ of the study group had insufficiency of the vitamin; $27 \%$ of the vitamin D deficient patients had very low levels below $10 \mathrm{ng} / \mathrm{mL}$. The present study found no effect of age on serum vitamin $\mathrm{D}$ concentration. 25-OH vitamin levels were suboptimal in diabetic patients pursuing indoor occupation compared to those with outdoor occupation. A trend of inverse insignificant association between vitamin D levels and duration of diabetes was observed. There was a positive correlation between serum vitamin D levels and sunlight exposure score and number of hours spent outdoors. The trend towards an association between serum 25-OHD levels and time spent outdoors suggest that production of vitamin $\mathrm{D}$ in the skin is the principal determinant of 25-OHD levels. The present study observed that the type 2 diabetic individuals with vitamin D deficiency showed a poor glycaemic control as evidenced by inverse relationship of serum vitamin D levels with FBSL and PPBSL values. The inverse association between the low serum 25(OH) D levels and elevated HBA1c in the study population may be inscribed into a wider context, portraying vitamin D deficiency as a poor prognostic factor, which may play a vital role in impairing the glycaemic control.

\section{REFERENCES}

[1] WHO. Global status report on non-communicable diseases 2010. Geneva: WHO 2011.

[2] Lalitha A, Tripathi MK. Impact of treating vitamin D deficiency on blood sugar levels in patients with type 2 diabetes and prediabetes. Paper presented at: APICON, 67th Annual Conference of the Association of Physicians of India 2012, Jan 12-15, Kolkata, India.

[3] Saedisomeolia A, Taheri E, Djalali M, et al. Association between serum level of vitamin $\mathrm{D}$ and lipid profiles in type 2 diabetic patients in Iran. J Diabetes Metab Disord 2014;13:7.
[4] Dalgård C, Petersen MS, Weihe $\mathrm{P}$, et al. Vitamin D status in relation to glucose metabolism and type 2 diabetes in septuagenarians. Diabetes Care 2011;34(6):1284-8.

[5] Doddamani GB, Umakant Boke, Kora S, et al. Serum vitamin $\mathrm{D}$ levels in newly detected type 2 diabetes mellitus. Sch J App Med Sci 2013;1(6):786-8.

[6] Bajaj S, Singh RP, Swivedi NC, et al. Vitamin D levels and microvascular complications in type 2 diabetes. Indian J Endocrinol Metab 2014;18(4):537-41.

[7] Joergensen C, Hovind P, Schmedes A, et al. Vitamin D levels, microvascular complications, and mortality in type 1 diabetes. Diabetes Care 2011;34(5):1081-5.

[8] Ahmadieh H, Azar ST, Lakkis N, et al. Hypovitaminosis $\mathrm{D}$ in patients with type 2 diabetes mellitus: a relation to disease control and complication. ISRN Endocrinol 2013;2013:641098.

[9] Shanthi B, Revathy C, Devi AJM, et al. Serum 25 OH D and diabetes mellitus. Journal of Clinical and Diagnostic Research 2012;6(5):774-6.

[10] Orwoll E, Riddle M, Prince M. Effects of vitamin D on insulin and glucagon secretion in non-insulindependent diabetes mellitus. Am J Clin Nutr 1994;59(5):1083-7.

[11] Scragg R, Sowers M, Bell C. Serum 25-hydroxyvitamin $D$, diabetes and ethinicity in the Third National Health and Nutrition Examination Survey. Diabetes Care 2004;27(12):2813-8.

[12] Chonchol M, Scragg R. 25-hydroxyvitamin D, insulin resistance, and kidney function in the Third National Health and Nutrition Examination Survey. Kidney International 2007;71(2):134-9.

[13] Lu L, Yu Z, Pan A, et al. Plasma 25-hydroxyvitamin D concentration and metabolic syndrome among middle-aged and elderly Chinese individuals. Diabetes Care 2009;32(7):1278-83.

[14] Tai K, Need AG, Horowitz M, et al. Glucose tolerance and vitamin D: effects of treating vitamin D deficiency. Nutrition 2008;24(10):950-6.

[15] Ford ES, Ajani UA, McGuire LC, et al. Concentrations of serum vitamin D and the metabolic syndrome among US adults. Diabetes Care 2005;28(5):1228-30.

[16] Chiu KC, Chu A, Go VL, et al. Hypovitaminosis D is associated with insulin resistance and beta cell dysfunction. Am J Clin Nutr 2004;79(5):820-5.

[17] Baynes KC, Boucher BJ, Feskens EJM, et al. Vitamin D, glucose tolerance and insulinaemia in elderly men. Diabetologia 1997;40(3):344-7.

[18] Hypponen E, Power C. Vitamin D status and glucose homeostasis in the 1958 British birth cohort: the role of obesity. Diabetes Care 2006;29(10):2244-6. 